\title{
El giro humanista del sistema de la moda
}

\section{Escobar Guanoluisa, Taña; Amoroso Peralta, Silvana}

Resumen:

El presente ensayo plantea una reflexión sobre el sistema de la moda: del pasaje de un sistema insostenible hacia uno sostenible. Replantea el paradigma consumista y frívolo de la moda hacia un sistema lento, simbólico, responsable y humanista. Trata cómo la moda pasó de ser un artefacto a un artificio gracias al sistema consumista y todo el perjuicio social y ambiental causado. Sin embargo, hace eco de la transformación del sistema de la moda bajo tres escenarios: transformar el producto, los sistemas y las prácticas del diseño. Finalmente, se identifican emprendimientos revolucionarios y transformadores del sistema de la

Cuadernos del Centro de Estudios de Diseño y Comunicación №76

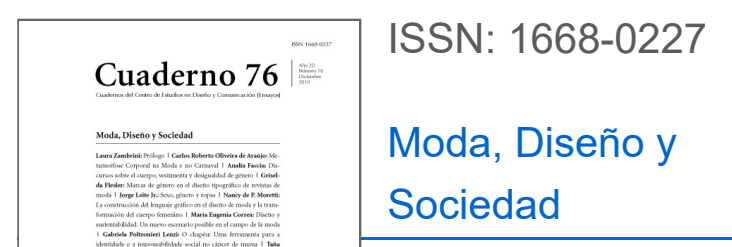

Año XX, Diciembre 2019, Buenos Aires, Argentina | 242 páginas

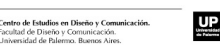

descargar PDF ver índice de la publicación

Ver todos los libros de la publicación

compartir en Facebook

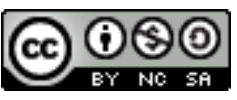
Esta obra está bajo una Licencia Creative Commons Atribución-NoComercialCompartirlgual 4.0 Internacional moda que son parte de esta metamorfosis social y de la humanización del sistema de la moda.

Palabras claves: moda - sostenible - trasformación - humanismo - artefacto.

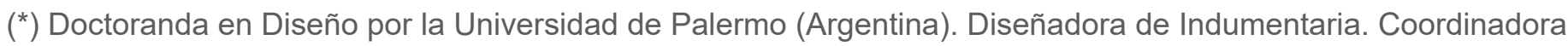
de la Unidad Operativa de Investigación de la Facultad de Diseño Arquitectura y Artes de la Universidad Técnica de Ambato (UTA). Docente investigadora en la Carrera de Diseño Textil e Indumentaria de la UTA. Autora de la Maestría en Diseño Desarrollo e Innovación de Indumentaria en el Ecuador. Diseñadora y Evaluadora de currículos relacionados con el sector textil confecciones, cuero y calzado. Dedicada al estudio de los sistemas indumentarios desde una perspectiva sociológica e histórica.

$\left.{ }^{(* *}\right)$ Diseñadora de modas. Maestrante en Estudios del Arte. Investigadora en teoría vestimentaria con especial enfoque en el objeto vestimentario y sus lecturas desde la semiótica, la filosofía y la sociología del vestido, así como el diálogo interdisciplinario entre arte y creación vestimentaria. Autora de "Vestimentario", una de las primeras investigaciones de semiótica de la vestimenta indígena en Ecuador. Directora de "Puchka", primer festival de vestimenta indígena del Ecuador. Docente de la Universidad del Azuay (UDA) en la carrera de Arte Teatral. 
Durante mucho tiempo, la moda fue vista como un fenómeno frívolo siendo acreedora del prejuicio científico, pues fue considerada un problema sustancialmente mundano. Sin embargo, desde el siglo XX, la moda, ya no pudo ser interpretada como una simple manifestación de las pasiones vanidosas del ser humano. Se convirtió en una de las instituciones rectoras de la modernidad y las sociedades consumistas, situación que la transformó en parte de un sistema: el sistema de la moda (Martínez Barreiro, 1998; Lurie, 2011; Godart, 2012). Según el diccionario, el término moda posee dos significaciones: en primer lugar, la moda es el uso o novedad que consigue una amplia aceptación; en segundo lugar, la moda en sentido estricto, es aquella que alude exclusivamente al fenómeno social vinculado al cambio del vestido (Martínez Barreiro, 1998). El presente artículo aborda la moda como un sistema en sentido estricto. De esta manera, la moda se caracteriza por ser un fenómeno de naturaleza social pues no sería factible sin sociedad ni grupo, así lo afirma Köing (1972) al situarla dentro de un conjunto de formas de comportamiento reguladas por un sistema específico de regulación social que se impone (Martínez Barreiro, 1998; Erner 2010; Bur, 2013). Según Bur (2013), la moda, no sólo refleja el estilo de una época, sino las opiniones dominantes, actitudes y valores de una sociedad. La moda, como un fenómeno propio de la modernidad, es un fenómeno sociocultural que emergió de la dinámica social industrial. Según Giusti (2009), en el final del siglo XX, surgió una investigación interdisciplinaria en torno a la moda en sentido estricto, la cual se ha denominado estudios de la moda o modología1. La modología es el encuentro de distintas ciencias sociales con la moda. Es unir el tiempo de la moda con el tiempo de la ciencia, aplicado al análisis de los hechos y la construcción de teorías. Así, el fenómeno sustancial de la moda, en sentido estricto, puede y debe ser un objeto de análisis científico. Entonces, el sistema de la moda como objeto de estudio, nos acerca al análisis desde diversas disciplinas: sociología, antropología, historia, entre otras. En el presente ensayo, el sistema de la moda es estudiado desde el punto de vista social, económico y ecológico. Social pues los sistemas indumentarios -como otros fenómenos- están implícitos y evidencian las connotaciones sociales de una época; económico y ecológico porque el sistema de la moda atraviesa un escenario de sistema insostenible hacia uno sostenible (Martínez Barreiro, 1996).

La vestimenta, del artefacto al artificio

Una de las definiciones de la palabra artefacto es la de un objeto elaborado con una determinada técnica cuya vida útil se desprende de una necesidad específica. Es decir, está hecho para un fin determinado. De este modo, una prenda de vestir debería servir para cubrir el cuerpo o protegerlo de la intemperie; no obstante, la historia del vestido va a mostrarnos que la vestimenta dista del hecho meramente práctico, "útil" y que, si bien, la vestimenta es usada para cubrirse, es decir, es artefacto, también funciona como artificio (Zambrini, 2010). En ese sentido, las primeras pieles de animales fueron usadas para abrigar y tuvieron una significación conforme al animal cazado. Es decir, invistió al traje de cualidades mágicas y divinas. En la contemporaneidad, también el vestido sigue funcionando en ese mismo nivel de artificio pues no ha quedado atrás la atribución mágica de la prenda de vestir. Es decir, la moda, siamesa del vestido, trasladó el campo de la cualidad divina a la interacción humana antropocéntrica. Es decir, el cuerpo ya no se inviste de atributos de otras especies animales, por ejemplo, de la fuerza de un oso, sino que requiere investirse de un estereotipo que le permita la pertenencia a un grupo social. Este estereotipo surge de una imagen elaborada de una persona ideal, un espejismo o una ilusión. En la sociedad contemporánea, ya no se caza la piel de otro animal, sino que se compra la imagen o se la adquiere por catálogo; investirse de ese ideal implica transformarse en consumidor. Ello supone cierta pasividad 
pues, a diferencia del cazador, ya no se sale a cazar sino que al sujeto consumidor le llegan las ofertas y es bombardeado por modelos culturales a seguir.

Una cultura de consumo

Si bien, la expresión "sociedad de consumo" suele usarse para referirse a la forma de consumo en las sociedades contemporáneas y occidentales; es importante anotar que el consumo como práctica no es un tema estricto de los tiempos modernos y que consumir implica conseguir algo (suele pensarse que una cosa) para satisfacer una necesidad. Si tomamos este rasgo básico del concepto consumo, se asume que todas las sociedades pueden ser consideradas de consumo:

Consumir, sea para fines de satisfacción de "necesidades básicas" y/o "superfluas" - dos categorías básicas en la comprensión de la actividad del consumo en las sociedades occidentales contemporáneas- es una actividad presente en toda y cualquier sociedad humana. En este sentido, una pregunta se interpone de inmediato: ¿Si todas las sociedades humanas consumen para poder reproducirse física y socialmente, si todas manipulan artefactos y objetos de la cultura material para fines simbólicos de diferenciación, atribución de estatus, pertenencia o gratificación personal, qué significa consumo en el rótulo sociedad de consumo? (Barbosa, 2004, pp. 7-8).

Livia Barbosa (2004) en su estudio sobre la sociedad de consumo enfatiza la diferencia entre sociedad y cultura de consumo. Es decir, manifiesta que son dos términos que no deben usarse como sinónimos, aunque se correspondan éstos expresan situaciones diferentes. En su texto, Barbosa afirma que las ideas en torno al consumo de autores tales como Bauman (2007) y Baudrillard (2009), concibieron la cultura del consumo dentro de la llamada sociedad posmoderna. Para algunos autores la sociedad de consumo es aquella que puede ser definida por un tipo específico de consumo, el consumo del signo o commodity sign, como es el caso de Jean Baudrillard. Sin embargo, debemos tener clara la distinción entre sociedad y cultura, porque para muchos autores -como Frederic Jameson (1991), Zygmun Bauman (2007), Jean Baudrillard (2009) y otros- la cultura del consumo o de los consumidores es una cultura de la sociedad posmoderna y el conjunto de temas discutidos sobre ese rótulo son bastante específicos. Ello incluye la relación íntima y casi casual entre consumo, estilo de vida, reproducción social e identidad, la autonomía de la esfera cultural, la estetización de la realidad, el signo como mercancía y el conjunto de atributos negativos atribuidos al consumo tales como: pérdida de la autenticidad de las relaciones sociales, materialismo y superficialidad, entre otros (Jameson, 1991; Bauman, 2007; Baudrillard, 2009). Por su parte, Zizek (2015), menciona que lo que se consume además es una ideología, lo que invita a pensar en el consumo incluso como una política. Para el tema del consumo de la vestimenta como moda, pensamos que es importante abordarlo desde la perspectiva de cultura de consumo, la chispa para ello se desprende de uno de los textos fundacionales de la mercadotecnia relacionada al impulso de la acción de consumo. Durante el período de posguerra, el asesor de marketing Victor Lebow, en su afán por proponer una política de recuperación y crecimiento económico de los Estados Unidos, escribió en el “Journal of Retailing” (1955), lo que pasó a ser el gran dogma del siglo XX y lo que va del siglo XXI. En su texto "Price Competition in 1955" Lebow (1955), plantó las bases discursivas para una cultura del consumo desbordado y como forma de vida. Enfatizó en el consumo rápido y la naturalización de esta acción en la sociedad contemporánea: nada más "normal" que consumir con urgencia. La célebre sección escrita dentro del subtema "The Real Meaning of Consumer Demand" rezaba: 
Nuestra economía enormemente productiva exige que hagamos del consumo nuestra forma de vida, que convirtamos la compra y el uso en rituales, que busquemos nuestras satisfacciones espirituales, nuestras satisfacciones de ego en el consumo. La medida del estatus social, aceptación social, el prestigio, ahora deben ser encontrados en nuestros patrones de consumo (...) Cuanto mayores sean las presiones sobre el individuo que se ajusta a normas sociales seguras más se inclina a expresar sus aspiraciones e individualidades en términos de lo que usa, conduce, come, su casa, su carro, su comida, sus prácticas preferidas. Esas comodidades y servicios deben ser ofrecidos al consumidor con especial urgencia (...) Necesitamos consumir cosas, desgastarlas, reemplazarlas y desecharlas a un ritmo cada vez mayor. Necesitamos tener gente que deba comer, beber, vestir, montar, vivir de una forma más complicada, lo que trae mayor consumo (Lebow, 1955, p. 3).

Este artículo también animaría a la publicidad como arma de manipulación social capaz de instar la gran necesidad de consumo, aunque como dirá Noam Chomsky (2017) en una entrevista para la pantalla: "La industria de las relaciones públicas, la industria de la publicidad, se dedica a la creación de consumidores", no se trata de una incitación a la acción de consumir solamente, sino, y sobre todo, un ser consumidor, continuando con Chomsky:

No iba a ser fácil controlar a una población por la fuerza (...) por lo tanto había que tener otros medios para controlar a la gente (...) tienes que controlarlos mediante el control de las creencias y actitudes. Una de las mejores maneras de controlar a la gente en términos de actitudes es lo que el gran economista Thostein Veblen (1944) Ilamó: "fabricando consumidores". Si puedes fabricar deseos, haciendo que obtener cosas que están a tu alcance sea la esencia de la vida, ellos [las personas] van a quedar atrapados, convirtiéndose en consumidores y se hace con gran sofisticación [refiere a campañas publicitarias] el ideal es lo que se ve ahora, donde digamos, los adolescentes, si tienen un sábado por la tarde libre, van a ir al centro comercial (Chomsky, 2017).

Hay una exigencia por consumir, es decir que se "debe" consumir y no a un ritmo determinado por el consumidor. El uso de la palabra libertad en el sistema económico actual ha permitido que el ideal del ser humano libre sea el estar atado indefinida y obligatoriamente al consumo de objetos simbólicos. Por supuesto, uno de estos objetos es la vestimenta engranada al sistema de la moda. A pesar que, las teorizaciones sobre la sociedad de consumo y la producción industrial desenfrenada tienen su mayor asidero en el siglo XX y XXI en relación a la moda, no podemos afirmar que el sistema tenga sus orígenes en las sociedades occidentales contemporáneas. Con la intención de hilar un tiempo histórico que fragua la noción de moda, es importante echar la mirada hacia su posible origen en el Renacimiento. Éste trajo consigo la vuelta al ser humano a través del antropocentrismo como dogma y no resultara extraño que las personas volvieran también los ojos a sus vestiduras y a la condición social que estas les predicaban. Junto a ello vino el afán de diferenciación que, poco a poco, encendió el motor del intercambio vestimentario en cuanto a parámetros de relación social, el intercambio comercial de fibras textiles y prendas. Con ello, tomó fuerza la dinámica de la diferenciación de clases y la imitación y el inagotable fluir del fenómeno moda vestimentaria, la idea de progreso ligado al término moderno y, a la sazón, trajo consecuencias inimaginables al sistema vestimentario en el que la velocidad cobró sentido. Fue en esa velocidad que la moda pudo por fin nacer, conectada con el cambio inminente (Saulquin, 2010, 2014; Croci, 2012).

La producción en serie fue uno de los hitos de la historia del vestido. La producción de indumentaria vio en la industrialización una respuesta a las angustias generacionales de la década de 1950, concretadas en la década 
de 1960 [es importante la relación entre lo sucedido en esta década con la aparición del paradigma de consumo de Lebow]. La ruptura del cordón umbilical generacional hizo que las prendas de vestir se diversificaran y se movilizaran de las pasarelas de las casas de alta costura a las boutiques de las calles de Londres, la moda estadounidense (mal llamada americana) comenzó a basarse en prendas de uso cotidiano como por ejemplo, los míticos pantalones de mezclilla o la camiseta. La ropa se dictaba desde las calles y la juventud se convirtió en foco comercial. Ello inició una "democratización" de gustos y se fue convirtiendo, a medida que avanzó el siglo XX, en una cacería de tendencias que cobró dimensiones brutales en el siglo XXI y en una sobreexplotación sin precedentes. El hacer prendas de moda es también hacer surgir el cambio. El par velocidad y cambio, se percibieron en sinónimos de progreso y modernidad, pero como ya se mencionó, no fue sólo hasta la década de 1950 que esta dinámica cobró verdadera forma con las ruptura generacionales y el surgimiento de la juventud como grupo con poder adquisitivo a los cuales se les ajustaba la calidad de la ropa para poder venderla a bajo costo y lograr que sea "accesible". Así, el surgimiento del "listo para usar" trajo un nuevo significado de comercio del traje con miras a la expansión sin límites en donde el surgimiento de la llamada Moda Rápida tuvo su asidero. La popularización y la diversificación de marcas (Zara, H\&M, Gap, Mango, Carters...) cuyo capital fue capaz de producir colecciones cada semana en una oferta salvaje en el que el consumidor encajó fácilmente en un frenético consumo. Un exceso de presente, un terror al pasado y un ansia por el futuro (Morgan, 2015).

\section{La moda corporativa}

Es común pensar en la moda como un fenómeno social. König en el prólogo a su Sociología de la moda (1972) escribió: "La moda es, en realidad, según se ha afirmado, un fenó- meno social total". Entonces, asumimos que la moda está inmiscuida en la forma en la que los seres humanos se relacionan en un determinado contexto y en el cual siempre están presentes relaciones de poder. De hecho, fue a partir de las fricciones en las relaciones de poder que la sociología tuvo su asidero y la sociología de la moda se abrió camino dando por sentado algunas consideraciones, entre ellas, que la moda se vincula directamente con el objeto vestimentario y que a pesar de que es un fenómeno social, que no sólo compete al vestido y sus modos en el devenir del tiempo (Perrot, 1981). La moda compromete al ser humano en su totalidad y lo evidencia de diferentes maneras en su interrelación social [pertenencia grupal, diferenciación colectiva, imitación, entre otras]. En este sentido, no es posible desprender al término moda del significado que tiene la vestimenta como producto sociocultural. Es en esa amalgama que la moda adquirió mayor fuerza y permitió importantes percepciones en torno a ella (Enwistle, 2002; Squicciarino, 2012). Así:

La moda no es en modo alguno tan solo una adición externa a la vida (para embellecerla o para afearla), sino que representa un medio esencial de regulación y de expresión de los seres humanos que viven en sociedad (...) La auto representación del hombre en la sociedad, su autoafirmación, tanto interna como externa, así como su clasificación y el deseo de distinguirse de su prójimo, desde que el hombre vive en sociedad, o sea, desde tiempo inmemorial, dependen en proporción realmente asombrosa de aquella misteriosa fuerza que designamos con la palabra moda (König, 1972, p. 13).

Por su parte, Godart (2012) manifiesta que el plantear una definición de la moda supone ciertas ambigüedades. En torno a la moda como una industria, apunta que ésta se constituye en una "actividad económica mayor", citando: “ (...) según la oficina de investigación de mercados Euromonitor Internacional, esta industria representa un $6 \%$ de la producción mundial" a lo que agrega: 
Más allá de su importancia como actividad económica, la moda representa a la vez un objeto social singular, en el que se entrecruzan las artes y la industria (...) Las casas de moda están abocadas diariamente a decisiones muy concretas, como son: fijar los precios de venta, localizar geográficamente sus fábricas, definir sus canales de distribución o aun la puesta en marcha de sus campañas publicitarias (...) La moda es una actividad económica porque produce objetos, pero es a la vez una actividad artística en cuanto produce símbolos. No se contenta con transformar un atuendo. Es creadora de objetos portadores de sentido" (Godart, 2012, pp. 1314).

Sería iluso negar que, de hecho la moda ligada a la vestimenta, permite imaginarios colectivos, construcciones de sentido, modifica las relaciones interpersonales y transforma los entornos. Cuando se manifiesta ese "más allá" se asume que lo mencionado anteriormente sobrepasa en la moda al tema económico, permitiendo dar por sentado que es el ser humano quien todavía mueve las cuerdas de las consecuencias sociales que pueden provenir del manejo industrial de este poderoso lenguaje. Se podría aventurar que ese más allá, es de por sí engañoso y que enmascara en otros aspectos (no menos importantes, por cierto). Algunas graves consecuencias, entre ellas una sociedad de consumo desbocada, importantes impactos ecológicos, la deshumanización del ser humano, la desaparición de la voluntad humana de relacionarse y relaciones de poder que sobrepasan al ser humano. Se propone por lo tanto, comprender a la moda contemporánea en el sentido de una moda corporativa partiendo de lo que una corporación significa. La RAE define una corporación como una organización compuesta por personas, pero también una compuesta por empresas que a su vez pueden estar compuestas por varias empresas pequeñas. Es decir, mientras más empresas pequeñas absorban, más poderosa será la corporación. Ello se traduce en mayores ingresos económicos como por ejemplo, en la industria de la moda, el Grupo Inditex (Ambiur, 2008).

El surgimiento de la corporación se relaciona con el surgimiento de la era industrial, ligándose irreductiblemente al negocio y a la idea occidental de éxito y progreso. Tiene como fin último el lucro y la búsqueda de beneficios económicos. En el aparato corporativo, en algún momento los sujetos permiten que este asuma el mando fabricando. Así una máquina autónoma que adquiere vida propia a partir de discursos legislativos o normas de ejecución, deja en algún momento de comprender que se trata de un grupo de personas y pasa a ser comprendida como el conjunto de empresas, así entre empresa y persona la brecha es profunda y en más de las veces irreconciliable (Achbar, 2003). En la moda y la dinámica de la sociedad de consumo, se puede percibir (y con especial énfasis desde las facilidades de compra electrónica) que ésta ya no puede catalogarse solamente como un fenómeno social sino que para las reflexiones en torno a ella, se hace urgente abordarla también como un fenómeno corporativo cuya objetivo final no va a ser el campo de las relaciones sociales y todas las complejidades que esto conlleva. La moda corporativa tiene su trinchera en el campo del consumidor transformando al ser humano en un segmento de mercado. Esto implica una desnaturalización y deshumanización del ser humano, negándolo así en su esencia; se pasa a una dinámica de desarrollo económico en donde la relación, ya no es ser humano con otro ser humano sino con la corporación (oferta) y consumidor (demanda). En la moda corporativa, más que una dinámica de consumo, existe una dialéctica de consumo pero esta dialéctica no produce un movimiento hacia delante, sino un avance cíclico y un movimiento hacía sí misma. Si hay un cambio de un estado a otro, llámese ciclo del producto, objeto-mercancía, intercambio comercial, transacción simbólica, está atrapado en una de las paradojas de la moda, la de su vida y su muerte, la de su novedad y caducidad instantáneas. Ello significa que por debajo de ese primer funcionamiento móvil, no se produciría en sí cambio alguno; el cambio de estado es una cortina de humo y un espectro sin 
contradicciones internas en la moda corporativa. El hecho contradictorio se da al nivel consumidor-consumidor pero la relación de poder corporación-consumidor permanece generalmente inmutable. Es una relación de poder curiosa, dado que el dominado no lucha por liberarse de su dominador; hay una fricción entre consumidores y el motor que mueve la moda se da en el avance del deseo de consumo. Como consecuencia de la moda corporativa, la vestimenta ligada a la moda se vincula ferozmente con la práctica casi ritualizada del usar y desechar en poco tiempo. Así la industria textil y la moda exigen la creación de prendas de microondas. Esta oferta y demanda desmedidas, que en muchos casos no pueden satisfacer a la demanda, ya sea por exceso de esta o por trucos publicitarios como los productos de ediciones limitadas, compete al campo de la moda rápida. Sus consecuencias han sido y son nefastas para la naturaleza y las especies vivas. Las más documentadas son aquellas que tienen que ver con la producción de la materia prima y la elaboración de prendas, trayendo consigo serios problemas, que van desde la esclavitud laboral, especialmente de niños y mujeres en condiciones infrahumanas como son los casos de las empresas textiles tercerizadoras que proveen a grandes marcas (Grupo Inditex, Nike, Adidas) en China, Bangladesh o Brasil. Incluso, son alarmantes los efectos de la contaminación ambiental, consecuencias que han modificado dramáticamente la vida en el planeta, tanto en términos sociales, culturales como biológicos y medioambientales.

Hasta aquí solo hemos puesto la atención en algunos actores de la producción de la vestimenta ligada a la moda, especialmente en el consumidor pero ¿qué pasa entonces con el diseñador de modas? En 2014, Lidewij Edelkoort, una de las mujeres más influyentes en el mundo de la moda occidental, publicó su manifiesto antifashion como una propuesta para la siguiente década, el manifiesto, titulado Anti_Fashion. Un manifiesto por la siguiente década. Diez razones por las que el sistema de la moda es obsoleto, y abarcaba algunas aristas que se entrecruzan en la producción de este fenómeno cultural, entre ellas la Educación, en torno a esto escribe:

Los institutos, academias, y universidades alrededor del mundo entrenan a sus estudiantes para convertirse en diseñadores de pasarelas, con un alto grado de individualidad, estrellas y divas para ser descubiertos por marcas de lujo (...) Las escuelas de moda están respondiendo a la actual demanda de lujo y mercado forzando a sus estudiantes a diseñar no solo ropa sino accesorios, joyas, ropa interior y un logo (...) entonces el tiempo queda corto, el proceso se comprime (...) ya no queda tiempo para considerar enfoques conceptuales (...) no queda tiempo para trascender la tendencia dominante (...) Las marcas necesitan diseñadores estrellas como el fútbol necesita jugadores estrellas. Los diseñadores estrellas ya no conocen como crear lo que en algún momento se conoció como moda (Edelkoort, 2014).

Así, cuando el consumismo se implantó como una tendencia de comportamiento el sistema de la moda se hizo insostenible. La insostenibilidad es un modelo económico que conquistó a la civilización industrial dentro del cual la moda rápida, junto a los sistemas de producción flexible, nos ha llevado a un modelo de producción acelerado que establece más cantidad por menos calidad. Un sistema que pasó por alto el daño al que está siendo sometido el ecosistema. Como lo indicó Kumar (2011): "El siglo XX fue el siglo de la ciencia y la tecnología. La época de crecimiento económico, el siglo del petróleo. En el siglo XXI estamos experimentando las consecuencias de los excesos del siglo anterior" (citado en Salcedo, 2014). La sociedad consumista contribuyó a la generación de un sistema de moda insostenible, caracterizado por la producción, el desarrollo masivo y el abuso de los recursos finitos del planeta. Según el criterio de Salcedo (2014), existe un problema de concepto pues se piensa que la naturaleza fue diseñada para proveer de manera infinita, sumado a un problema de comportamiento, pues aún no se entiende cuánta naturaleza es necesaria para mantener las prácticas de consumo. Pero ¿hay alguna salida de escape? Parecería que estamos condenados al consumo en los términos 
que se han expuesto y que como diseñadores de moda adoctrinados para no reflexionar, para no hacerse preguntas, para no desestabilizar el statu quo, no parece existir una salida; no obstante, es urgente encontrar la fisura y el intersticio a través del cual podamos procurarnos un buen vivir. Una visión holista de la profesión es urgente y la responsabilidad de la academia debe basarse en un firme compromiso en educar para la libertad, la consciencia, el desarrollo del humanismo y en términos integrales, la protección de la vida y la sostenibilidad medioambiental. En esa línea, se recalca que en la producción de moda-vestido-textil ha venido dando un giro más humano a partir de la vuelta a las prácticas artesanales y filosofías diversas. Lo ancestral ha provocado la tendencia que podría nombrarse filosofía de Moda Lenta. Afortunadamente, el paradigma del sistema de la moda comienza a ser replanteado. La macro tendencia hacia la sostenibilidad pretende transformar la manera de hacer negocios en la moda, reorientar los métodos de producción y reinventar las prácticas del diseño, haciéndolos sostenibles en el tiempo. Para que la moda lenta sea vista como "un renacimiento económico, cultural y social" el diseñador y los actores enrolados en el sistema de la moda tienen la responsabilidad social de ser los impulsores de este cambio social y cultural. Es decir, impulsores de la transformación en la forma de pensar y hacer la indumentaria (Fletcher, 2012). Como metodologías establecidas para conseguir la transformación del sistema de la moda se plantean las escritas por Fletcher (2012), Gwilt (2014) y Salcedo (2014). Al respecto, Fletcher (2012) propone que el cambio del sistema de moda insostenible a uno sostenible. Viene de la mano de las transformaciones de productos de moda, de los procesos y de las prácticas del diseño. Indica el valor que tiene, dentro de este sistema, el diseño con enfoque local y regional. Dentro de la cadena de valor de los productos indumentarios nos anima a pensar en el abastecimiento de materiales dentro de nuestra localidad. Para Salcedo (2014), la gestión de la moda sostenible puede darse a través de: pensar en el desmontaje de la prenda, crear lazos emocionales con el producto indumentario, generar el bienestar social de los trabajadores, minimizar las mermas, gestionar la durabilidad en la prenda y los residuos. Mientras que Gwilt (2014) propone la reorientación del ciclo de vida de un producto abierto a un ciclo cerrado, mediante la adaptación de procesos que nos permitan la revalorización, reutilización y el reciclaje.

\section{La humanización de la moda en Ecuador}

En el Ecuador existen empresas que apuestan a la producción con responsabilidad social. Las mismas han implementado una forma de producciones sociales, ambiental y econó- micamente responsables enmarcadas bajo el concepto de moda ecológica, moda ética, moda lenta y moda sostenible. Así, desarrollan sistemas que tienen en cuenta, no sólo al medio ambiente, sino que también la salud de los consumidores y las condiciones laborales de las personas de la industria de la moda. Estas empresas se dedican al diseño y producción de prendas que valorizan lo hecho a mano; a la vez que toman en cuenta los términos ambientales por minimización de contaminación, contribuyen al bienestar del usuario brindando prendas de calidad y aportan a la recuperación de los conocimientos ancestrales de pueblos, nacionalidades y comunidades indígenas de Ecuador. El concepto de responsabilidad de estas empresas consiste en respetar la vida de las mujeres: madres, esposas y artesanas. Un respeto a sus condiciones de vida, su integridad y sus ingresos económicos. Rescatan el comercio justo y son activistas del diseño con responsabilidad social. Son claras referentes en la transformación social del producto y de la humanización de la moda. Además, como aporte significativo, estas empresas son consideradas como Iniciativas de salvaguardia y promoción del Patrimonio Cultural Inmaterial del Ecuador. (Fletcher, 2012; Gwilt, 2014; Salcedo, 2014; INPANC-CAB, 2015, 2016). Transformar el sistema de la moda en Ecuador, implica observar los sistemas indumentarios como un elemento esencial en la construcción identitaria de los grupos sociales y de los individuos. Profundizar el diseño regional con insumos, materiales y 
manufactura local con el fin de que el nuevo sistema de la moda suministre signos para que, en unión con otros campos culturales se construya y refleje la identidad ecuatoriana (Fletcher, 2012; Godart, 2012; INPANC-CAB, 2016).

Para apoyar este renacimiento económico y cultural, algunos emprendimientos tales como Dominga, Paqocha y EliJuma en Ecuador nos ejemplifican con su responsabilidad social. Por ejemplo, Dominga, es una empresa dedicada al diseño y producción de prendas bordadas a mano por artesanas de Zuleta. Sus piezas indumentarias son creadas con el objetivo de incorporar elementos tradicionales que trasmitan la cultura y den a conocer técnicas artesanales ancestrales de las diversas nacionalidades del Ecuador. Buscan plasmar los saberes ancestrales en blusas bordadas por aproximadamente 25 mujeres artesanas que participan en los procesos de diseño, confección, bordado y comercialización. Dominga promueve una perspectiva de comercio justo y posee una organización de negocio horizontal.

Por su parte, Paqocha, desarrolla indumentaria tejida en telares artesanales de la región central del país. Fue fundada con el objetivo de cambiar la realidad de las comunidades alpaqueras en Ecuador, pues dentro de su proceso de producción, cría las alpacas, las esquila y clasifica la fibra que posteriormente, se entrega a mujeres obreras de las comunidades de Guamote, Chimborazo, para la hilatura a mano, con guango y huso. Los ovillos son teñidos con productos naturales, los mismos que luego pasan a manos de mujeres de la zona urbana para dar forma a la pieza vestimentaria a través del tejido. Su colección de prendas son sacos, bufandas, cuellos, vestidos, gorras y mitones. Las tejedoras son de las ciudades de Riobamba, Quito y Mira. Respetan el tiempo de elaboración y entregan un pago justo a sus colaboradoras. A su vez, el emprendimiento emergente de EliJuma, nació por la iniciativa de la diseñadora Elizabeth Juma. El amor a su tierra la empujó a mirar la ardua labor que desempeñan las artesanas de la comunidad de Zuleta y a valorizar el trabajo elaborado por hábiles manos: el bordado. Interesada además en diseñar y producir indumentaria con responsabilidad social, emprendió desde el 2015 su propio negocio, enmarcado dentro de la moda lenta. Así, rescata los remanentes de las blusas bordadas y las reutiliza en diversas prendas de vestir. En suma, nos emociona que el sistema de la moda y el diseño de indumentaria en Ecuador sea testigo de esta humanización de la moda.

\section{Conclusiones}

Los estudios de moda o modología, llegan a institucionalizar la moda en sentido estricto. Pues favorecen la construcción de teorías que, apoyadas en las ciencias sociales, nos permiten dejar detrás la frivolidad con la que han sido tratados los sistemas indumentarios y verlos como un fenómeno sustancial que merece ser objeto de análisis científico. Apoyado en esto, el presente ensayo propuso la necesidad de estudios sobre los sistemas indumentarios, desde la dimensión del diseño apoyado en las ciencias sociales, humanas y las ingenierías. Éstos fortalecerán la profesión y, por ende el sistema y los productos de moda indumentarios en Ecuador. Interpretar el fenómeno de la moda en sentido estricto nos llevó a preguntarnos ¿por qué nos vestimos? o si ¿existen leyes capaces de interpretar los cambios vestimentarios? Tales cuestionamientos han sido tratados por diversos soció- logos, desde su perspectiva filosófica clásica, moderna y posmoderna. Y sin importar la época de estudio, han llegado a la conclusión que la moda es un fenómeno sociocultural que emerge de la dinámica social y es un elemento esencial en la construcción identitaria. La moda es, a su vez, un fenómeno económico característico de occidente y de la modernidad. La exigencia y urgencia de estas sociedades consumistas han ligado al ser humano al consumo de objetos simbólicos, siendo uno de éstos la vestimenta engranada en el sistema de la moda. Nos liga a ella el modelo de desarrollo consumista adoptado por las sociedades 
latinoamericanas. Las consecuencias que devienen del desarrollo industrial y la moda han causado graves impactos ecológicos y la deshumanización del ser humano. La velocidad es el leitmotiv que provocó el paso de un sistema vestimentario, productor de indumentarias artefactos, a un sistema de la moda, productor de indumentarias artificios.

Afortunadamente, el sistema de la moda se replantea, renace y humaniza social, econó- mica y culturalmente. La sostenibilidad pretende trasformar el producto, los sistemas y la práctica del diseño. Cuando nos adentramos en el negocio de la moda, se hace necesario emplear estrategias que nos permitan determinar con acierto ¿Cómo orientar nuestro emprendimiento al negocio de la moda? Y en medio de este sistema insostenible platearnos con acierto la pregunta ¿Cómo contribuir al sistema sostenible de la moda con nuestro emprendimiento? ¿Cómo comulgar con la filosofía de la moda lenta con nuestro producto indumentario? Ser un transformador del sistema y gestionar la sostenibilidad en la industria de la moda ecuatoriana es un reto. Al paradigma de la moda fundamentado en "transformar la manera de hacer negocios, a rediseñar los métodos de producción y reinventar las prácticas de diseño de modo que sean sostenibles en el tiempo" (Salcedo, 2014 p. 13), se alinean estas empresas de moda lenta que representan la ruptura de las prácticas actuales en el sector de la moda. Estas empresas son un claro ejemplo de la transformación social del producto y del nuevo rumbo que está tomando la moda en Ecuador, pues aportan a la transformación del sistema de la moda, a través de sus productos indumentarios y reconvierten el sistema de la moda. Demuestran respeto y responsabilidad social con la naturaleza mediante la utilización de bases textiles, insumos y procesos que son amigables con el medio ambiente. Potencian el amor por el diseño local pues sus piezas indumentarias evidencian un apego a la valoración y difusión del diseño local. Su filosofía de negocio fomenta una nueva infraestructura para trabajar en una producción en series cortas. A la vez, emplean la técnica artesanal para realizar productos con artesanos del sector utilizando materia prima y mano de obra del lugar. Estas empresas referentes en el país mantienen una relación de confianza con el artesano garantizando un producto de calidad. Son activistas de la moda lenta y portan la bandera de este modelo de negocio transformador y de comercio justo. Si todos los actores sociales: agricultores, políticos, artesanos, académicos, químicos, empresarios y diseñadores aportamos desde nuestra área a la transformación del sistema de la moda, seremos activistas de la moda ecológica, la moda ética, la moda lenta y la moda sostenible. Colaboraremos, además con el diseño regional, potencializando una cultura de diseño socialmente responsable, pero sobre todo, aportaremos a la humanización del sistema de la moda.

Notas

1. Según Wakamura (2005), estas expresiones son nombradas como "fashion studies" o "fashion ologi".

Referencias Bibliográficas

Achbar, M. Et (2003). Corporaciones. ¿Instituciones o psicópatas? [documental]. Canadá.

Ambiur, G. (2008). Diccionario visual de la moda. Singapur: Editorial Gili.

Barbosa, L (2004). Sociedad de consumo. Río de Janeiro.: Jorge Zahar Editor.

Baudrillard, J. (2009). La sociedad de consumo. Madrid: Siglo XXI de España Editores.

Bauman, Z (2007). Vida de consumo. México D.F:: Fondo de cultura económica. 
Brown, S. (2013). Refashioned. Barcelona: Blume.

Bur, A. (2013). Moda, estilo y ciclo de vida de los productos de la industria textil. En C. d. Comunicación, Cuaderno 45 (págs. 143-147). Buenos Aires: Centro de Estudios en Diseño y Comunicación.

COM. (2010). El libro verde. Liberar el potencial de las industrias creativas y culturales. Brúselas: COM.

Croci, P. (2012). Los cuerpos dóciles. Hacia un tratado sobre la moda. Buenos Aires: La marca editora.

Edelkoort, L (2014). Anti_Fashion. A manifestó for the next decade. Ten reasons why the fashion system is obsolete.

Entwistle, J. (2002). El cuerpo y la moda. Una visión sociológica. Barcelona: Paidos.

Erner, G. (2010). Sociológia de las tendencias. Barcelona: Gustavo Gili.

Fletcher, K., \& Grose, L. (2012). Gestionar la sostenibilidad en la moda. Barcelona: Editorial Blume.

Godart, F. (2012). Sociología de la moda. Buenos Aires: Edhasa.

Gwilt, A. (2014). Moda Sostenible. Barcelona: Gustavo Gili.

INPANC-CAB. (2015 - 2016). Iniciativas de salvaguardia y promoción del Patrimonio Cultural Inmaterial. Salvaguardia del Patrimonio Cultural a la Vanguardia del Siglo XIX, 10-28.

Jameson, F. (1991). Postmodernism or, The cultural logic of late capitalism. Carolina del Norte: Duke University Press Durham.

König, R. (1972). Sociología de la moda. Barcelona.: A. Redondo, editor.

Lebow Víctor (1955). Journal of Retailing. Sring 1955. (Price Competition in 1955)

Luire, A. (2011). El lenguaje de la moda. Una interpretación de las formas de vestir. Barcelona: Paidos.

Martínez Barreiro, A. (1996). Elementos para una teoría social de la moda. Revista de pensamiento social, 97124.

Martínez Barreiro, A. (1998). La moda en las sociedades modernas. Mirar y hacerse mirar. Madrid: Tecnos.

Morgan, A. (director). (2015). The True Cost [documental]. Estados Unidos.: Life is my movie Entertainment Company.

Papanek, V. (2014). Diseñar para el mundo real. Cataluña: Pol-len.

Perrot, P. (1981). Elementos para otra historia del vestido. Diogénes N 114, 159-11. 
Salcedo, E. (2014). Moda ética para un futuro sostenible. Barcelona: Gustavo Gili.

Saltzman, A. (2009). El cuerpo diseñado. Sobre la forma en el proyecto de la vestimenta. Buenos Aires: Paidos.

Saulquin, S. (2010). La muerte de la moda, el día después. Argentina: Paidos.

Saulquin, S. (2014). Política de las apariencias. Nueva significación del vestir en el contexto contemporáneo. Buenos Aires: Paidos.

Squicciarino, N. (2012). El vestido habla. Consideraciones psico-sociológicas sobre la indumentaria. Madrid: Cátedra.

Veblen, T (1944). La teoría de la clase ociosa. México D.F: Fondo de cultura económica.

Zambrini, L. (2010). Modos de vestir e identidades de género: reflexiones sobre las marcas culturales del cuerpo. Revista de Estudios de Género Nomadías. Nro. 11, 130-149.

Material audiovisual

Noam Chomsky. Habla sobre la creción de "Consumidores que aceptan ser controlados". Subido a youtube por Re-Conexión el 8 de abril de 2017. https://www.youtube.com/ watch?v=cYuool7985E visto por última vez el 25 de mayo de 2017.

Zizek Slavoj. "Sobre el consumismo". Subido a youtube por Claudio Álvarez Terán el 22 de febrero de 2015. https://www.youtube.com/watch?v=TawLAkolF7Q última fecha de consulta. 25 de mayo de 2017.

My Litle Pony. Temporada 5. Capítulo 14. "Boutique Canterlot”. https://www.youtube.com/ watch? $\mathrm{v}=\mathrm{erNiMiVNDVg}$

Abstract: This essay proposes a reflection in the fashion system, the passage from an unsustainable system to a sustainable one. Rethink the consumerist and frivolous paradigm of fashion to a slow, symbolic, responsible and humanistic system. It deals with how fashion became an artifact to an artifice thanks to the consumerist system and all the social and environmental damage caused. However, it echoes the transformation of the fashion system under three scenarios: transforming the product, systems and design practices. Finally, we identify revolutionary undertakings and transformers of the fashion system that are part of this social metamorphosis and the humanization of the fashion system.

Key words: fashion - sustainable - transformation - humanism - artifact.

Resumo: O presente ensaio plantea uma reflexão sobre o sistema da moda: do pasto de um sistema insustentável para um sustentável. Replantea o paradigma consumista e frívolo da moda a um sistema lento, simbólico, responsável e humanista. Trata-se de como a moda passou de ser um artefato a um artifício graças ao sistema consumista e a todo o perjuicio social e ambiental causado. Sim embargo, faz eco da transformação do sistema da moda sob três cenários: transforma o produto, os sistemas e as práticas do projeto. Finalmente, 
identifique-se identificadores e transformadores do sistema da moda que são parte de esta metamorfose social e da humanização do sistema da moda.

Palavras chave: moda - sustainable - trasformación - humanismo - artefato.

[Las traducciones de los abstracts fueron supervisadas por el autor de cada artículo]

El giro humanista del sistema de la moda fue publicado de la página 119 a página132 en Cuadernos del Centro de Estudios de Diseño y Comunicación N76 